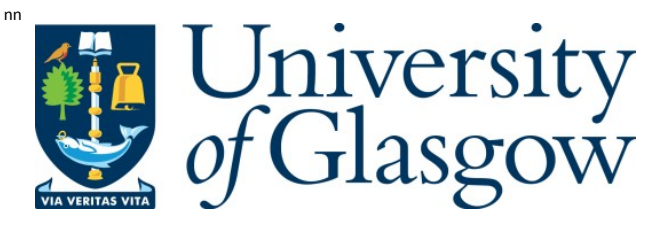

Clark, J. S., Delion, L., and Farrugia, L. J . (2015) Synthesis of four diastereomers of sclerophytin $f$ and structural reassignment of several sclerophytin natural products. Chemistry: A European J ournal, 21(12). pp. 4772-4780.

Copyright @ 2015 Wiley-V CH Verlag

A copy can be downloaded for personal non-commercial research or study, without prior permission or charge

Content must not be changed in any way or reproduced in any format or medium without the formal permission of the copyright holder(s)

http://eprints.gla.ac.uk/103783/

Deposited on: $06 \mathrm{M}$ arch 2015

Enlighten - Research publications by members of the University of Glasgow http://eprints.gla.ac.uk 


\title{
Synthesis of Four Diastereomers of Sclerophytin F and Structural Reassignment of Several Sclerophytin Natural Products
}

\author{
J. Stephen Clark*, Laëtitia Delion and Louis J. Farrugia ${ }^{[a]}$
}

Abstract: The synthesis of the triol that has been proposed to be the marine natural product sclerophytin $F$ has been completed along with the syntheses of three diastereomers. Comparison of the NMR data for all four compounds to the data reported for the natural product reveals that sclerophytin $\mathrm{F}$ is not the $3 \mathrm{~S}$ diastereomer of sclerophytin A as proposed by Friedrich and Paquette. Re-analysis of the NMR data for known sclerophytin natural products and synthetic analogues leads to the conclusion that sclerophytins $E$ and $\mathrm{F}$ are the same compound. This finding has allowed structural reassignment of several other cladiellin natural products.

\section{Introduction}

The cladiellins (also termed eunicellins) are a large family of C-2,C-11 cyclised ether-bridged cembranoids that have been isolated from various marine invertebrates. ${ }^{[1]}$ The compounds display significant structural diversity with regard to the type and position of substituents adorning the $\mathrm{C} 20$ skeleton and exhibit a range of biological activities. Members of the sclerophytin subclass of the cladiellin natural products possess a high degree of oxygenation in the medium-ring and have ester or hydroxyl groups located at the C-3, C-6 and C-7 positions (Figure 1). ${ }^{[2,3]}$

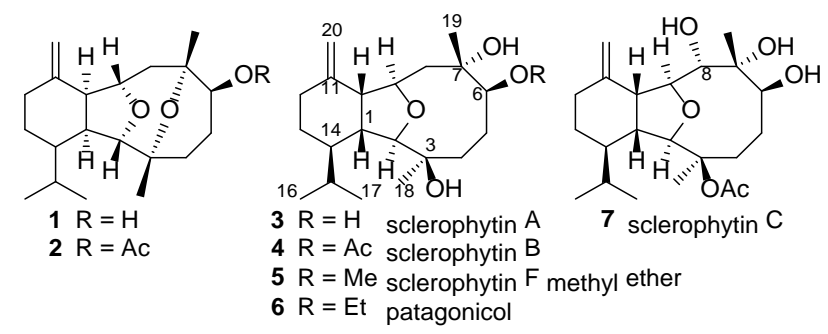

Figure 1. Originally proposed structures (1 and 2 ) for sclerophytins $A$ and $B$, and five sclerophytins (3-7) the structures of which have been confirmed by synthesis or X-ray analysis.

The first members of the sclerophytin sub-class to be isolated were sclerophytins A and B (Figure 1). ${ }^{[2]}$ These compounds were reported to be doubly ether-bridged compounds with the stereochemically ambiguous structures $\mathbf{1}$ and 2 (Figure 1) Sclerophytin A was reported to display potent activity against the L1210 leukemia cells at a concentration of $1 \mathrm{ng} \mathrm{mL}^{-1}$. ${ }^{[2]}$

Contemporaneous synthetic studies by the research groups of Paquette and Overman showed that the structures (1 and 2) assigned to sclerophytins $A$ and $B$ were incorrect. ${ }^{[4]}$ After painstaking detective work, Paquette, Overman and their coworkers deduced that sclerophytin $A$ is the triol $\mathbf{3}$ and that sclerophytin B is the C-6 acetate (4), then synthesised both natural products to prove their structures (Figure 1)..$^{[4-g]}$ Several other groups have verified the structures of sclerophytins $A$ and $B$ by total synthesis, ${ }^{[5]}$ and the structures of the closely related natural products sclerophytin F methyl ether (5) (which should be re-named sclerophytin A methyl ether) and patagonicol (6) have been confirmed by X-ray crystallography (Figure 1). ${ }^{[6,7]}$

In 1989, Alam and co-workers isolated and characterized four additional sclerophytins (C-F) from the soft coral Sclerophytum capitalis; the structure of sclerophytin $C(7)$, which bears an additional hydroxyl group at C-8, was confirmed by $\mathrm{X}$-ray crystallography (Figure 1). ${ }^{[3]}$ The research groups of Ochi and Shibata, and of Rao and Faulkner isolated several compounds of the same type, including litophynin E, 6-acetoxy litophynin E, 6-ethoxy sclerophytin E and 6-isovaleroyl sclerophytin E, from soft corals and also re-isolated some of the sclerophytins that had been discovered by Alam and co-workers. ${ }^{[8-10]}$

In 2002, Friedrich and Paquette raised doubts about the stereochemical assignments given to sclerophytins $E$ and $F$ by Alam and co-workers and also the assignments given to litophynin E, 6-acetoxy litophynin E, 6-ethoxy sclerophytin E and 6-isovaleroyl sclerophytin E. ${ }^{[1]}$ Friedrich and Paquette reanalysed the NMR data for all members of the sclerophytin family and concluded that sclerophytin $E$, sclerophytin $F$, litophynin E, 6-acetoxy litophynin E, 6-ethoxy sclerophytin E and 6-isovaleroyl sclerophytin E are compounds 8-13 (Figure 2) possessing inverted configuration at C-3 compared to sclerophytins A and B (Figure 1). Friedrich and Paquette based their structural reassignments for the whole group mainly on the basis of the large ${ }^{13} \mathrm{C}$ NMR chemical shift differences (+11.8 and $-7.1 \mathrm{ppm}$ ) between the peaks arising from $\mathrm{C}-3$ and $\mathrm{C}-18$ in the supposed triol sclerophytin $F$ when compared to the corresponding peaks in ${ }^{13} \mathrm{C}$ NMR spectrum of sclerophytin $\mathrm{A} .{ }^{[1]]}$

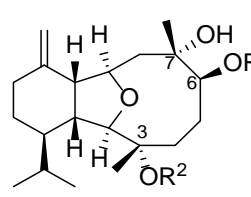

$8 R^{1}=H \quad R^{2}=A C$ $10 \mathrm{R}^{1}=\mathrm{H} \quad \mathrm{R}^{2}=\mathrm{CO}$ - $\mathrm{Pr}$ litophynin $\mathrm{E}$ $11 \mathrm{R}^{1}=\mathrm{Ac} \mathrm{R}^{2}=\mathrm{CO}$ - $\mathrm{Pr}$ 6-acetoxy litophynin $\mathrm{E}$ $12 \mathrm{R}^{1}=\mathrm{Et} \mathrm{R}^{2}=\mathrm{Ac} \quad$ 6-ethoxy sclerophytin $\mathrm{E}$ $13 \mathrm{R}^{1}=$ COi-Bu $\mathrm{R}^{2}=\mathrm{Ac}$ 6-isovaleroyl sclerophytin $\mathrm{E}$

Figure 2. Structures of various sclerophytin diterpenes proposed by Paquette and Friedrich (ref. 11). 


\section{Results and Discussion}

At the outset, our objective was to confirm or disprove the reassigned structure of sclerophytin $\mathrm{F}$ by synthesising the triol 9. ${ }^{[12]}$ Retrosynthetic analysis of this compound was undertaken as shown in Scheme 1. Replacement of the hydroxyl groups at C-6 and C-7 with an alkene and masking of the C-3 hydroxyl group leads to the diene $\mathbf{i}$. Removal of the methylene group (C20) and replacement of a side-chain methyl substituent with a carbonyl group reveals the diketone ii. Replacement of the C-11 carbonyl group with an enol ether spanning C-10-C-11 leads to the ketone iii and Diels-Alder bond disconnection at C-12-C-13 and $\mathrm{C}-14-\mathrm{C}-1$ affords the diene iv. Disconnection through the alkoxy diene of iv leads to the ketone $\mathbf{v}$, a key intermediate in our synthesis. The bridged-bicyclic ether structure of $\mathbf{v}$ can be simplified to reveal the diazo ketone vi and removal of the diazomethyl group and the silyl ether leads to the tetrahydropyranol vii. Disconnection between the positions 2 and 3 on the ring gives the vinylogous carbonate viii, which is analogous to an early intermediate in our previous total syntheses of related cladiellin natural products. ${ }^{[5 c, 13]}$<smiles>C=C[C@H]1O[C@H]2C[C@](C)(O)[C@@H](O)CC[C@H](O)[C@]2(C)[C@@H]1C(C)C</smiles>

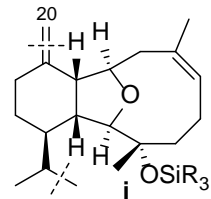

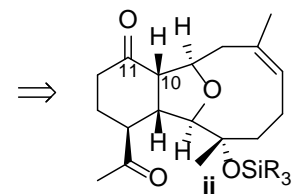

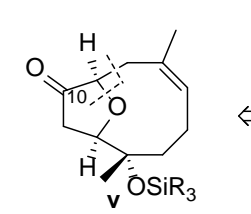

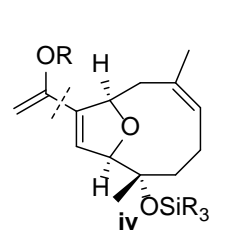

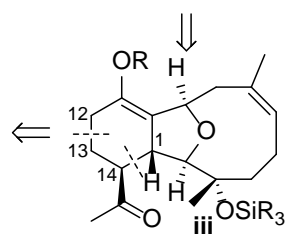

$\Downarrow$<smiles>[R5]O[C@@]1(C)CC[C@@H](C(=C)C)OC1CC(=O)C=C</smiles><smiles>[R]OC(=O)C[C@]1([14CH])O[C@H](C(=C)C)CC[C@]1(C)O</smiles><smiles>[R]OC(=O)/C=C\O[C@@H](CCC(C)=O)C(=C)C</smiles>

Scheme 1. Retrosynthetic analysis of the proposed structure of sclerophytin F. compared to related substrates, resulting in poor yields and low levels of diastereocontrol.

The synthesis of the a-diazo ketone 19 , the intermediate that would serve as the substrate in the key ring-forming reaction, commenced from the alcohol 14 (91-96\% ee) (Scheme 2). This compound had been used an intermediate during our syntheses of related cladiellin natural products including sclerophytins $A$ and $B{ }^{[5,13]}$ Oxidation of the alcohol 14 with pyridinium chlorochromate (PCC) afforded the aldehyde 15 and subsequent sequential nucleophilic addition of trimethylaluminium and Swern oxidation afforded the methyl ketone 16. Treatment of the ketone $\mathbf{1 6}$ with samarium(II) iodide resulted in reductive cyclisation of the ketone on to the vinylogous carbonate to provide the tetrahydropyranol 17 in excellent yield ( $>12: 1$ selectivity). ${ }^{[14]}$ Protection of the alcohol as a TBS ether afforded the ester $\mathbf{1 8}$ and this was converted into the corresponding carboxylic acid under basic conditions. The $\alpha-$ diazo ketone 19 was obtained by sequential reaction of the carboxylic acid with isobutylchloroformate and treatment of the resulting mixed anhydride with diazomethane (Scheme 2).

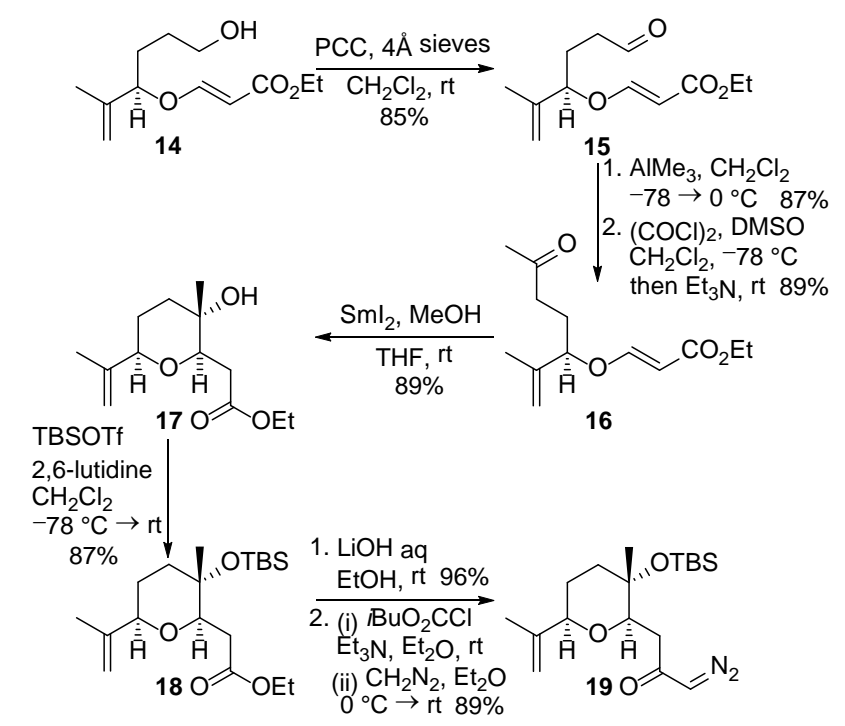

Scheme 2. Synthesis of diazo ketone 19, the substrate for the key cyclisation and rearrangement reaction.

The ketone 16 required for the reductive cyclisation reaction could be prepared from a commercially available lactone instead (Scheme 3). Lactone 20, the antipode (S enantiomer) of the requisite starting material, was used to explore the viability of the route because it is more readily available than the $R$ enantiomer. Conversion of the carboxylic acid into the acid chloride and treatment with methylmagnesium bromide delivered the methyl ketone 21. ${ }^{[15]}$ Subsequent Wittig methylenation afforded the known alkene $22^{[15 a]}$ and this compound was converted into (S)16 by ring opening with methylithium and treatment of the resulting alcohol with ethyl propiolate and $\mathrm{N}$-methylmorpholine. Although this route to the ketone $\mathbf{1 6}$ was shorter than the original one, the product was found to have low ee, presumably due to 
partial racemisation during formation or methylenation of the ketone 21. Further optimization of the route was not performed because the original route was deemed to be satisfactory for the production of large quantities of the ketone $\mathbf{1 6}$ with high ee.

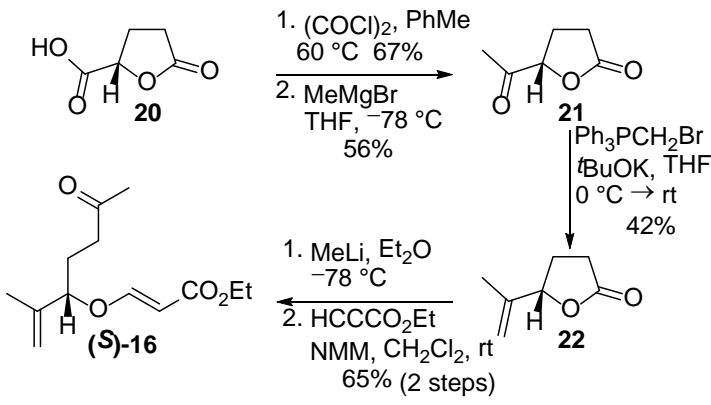

Scheme 3. Synthesis of the ketone (S)-16 starting from the commercially available lactone 20.

In previous work, we had shown that copper- or rhodiumcatalysed reactions of the $\alpha$-diazo ketone 23 (lacking a C-3 methyl group) deliver the isomeric bridged-bicyclic ethers $Z$ - and $E-24$ in excellent yield and that the product ratio is dependent on the metal complex employed as the catalyst and the reaction conditions (Scheme 4). ${ }^{[\mathrm{cc}, 13 \mathrm{~b}, 16]}$ We had also shown that the reaction of the $\alpha$-diazo ketone 23 can be tuned to give either $Z$ or $E-24$ as the major product ( $>6: 1$ selectivity) by selecting the appropriate catalyst and solvent. However, it was unclear what influence the methyl substituent at the 3-position of the tetrahydropyran would have on the reaction yield or the product ratio. It was conceivable that the substrate 19 would undergo the key reaction in poor yield and/or deliver the isomeric products with low selectivity.

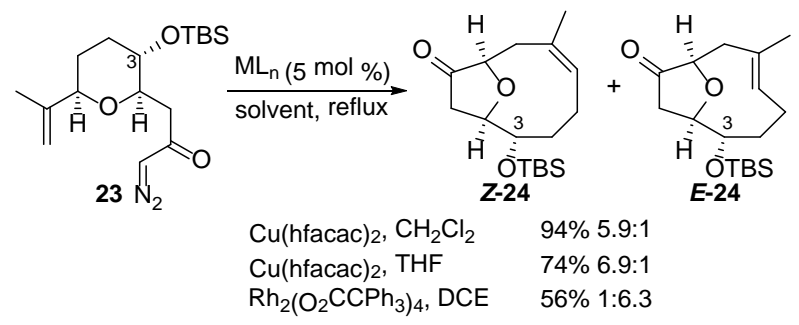

Scheme 4. Metal-catalysed reaction of the a-diazo ketone 23 and rearrangement of the resulting ylide or metal-bound ylide to give the bridgedbicyclic ethers Z-24 and E-24.

The metal-catalysed reaction of the a-diazo ketone $\mathbf{1 9}$ to give the isomeric bridged-bicyclic ethers $Z-25$ and $E-25$ was explored In preliminary experiments, a copper or rhodium complex was employed as the catalyst and reactions were performed in dichloromethane at reflux (Scheme 5 and Table 1). In contrast to what had been observed for reactions of the a-diazo ketone $\mathbf{2 3},^{[5 c, 13 \mathrm{~b}]}$ the $Z$-isomer $(\mathbf{Z}-\mathbf{2 5})$ was the major or sole product in every case. The highest yield (98\%) was obtained when
copper(II) hexafluoroacetylacetonate was employed as the catalyst, but the diastereoselectivity $(1.8: 1, Z: E)$ was low (entry 2 , Table 1). The use of rhodium(II) acetate as the catalyst afforded a higher degree of selectivity $(7.5: 1, Z: E)$ but the yield was less impressive (entry 3 , Table 1 ). The $Z$-isomer was obtained exclusively when rhodium(II) triphenyl acetate was employed as the catalyst, but in this case the yield was very low (entry 8 , Table 1)

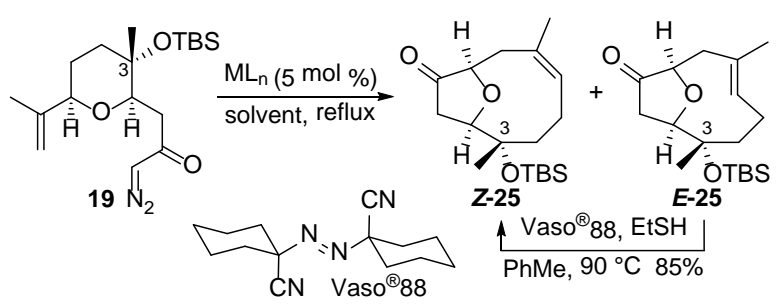

Scheme 5. Metal-catalysed reaction of the $\alpha$-diazo ketone 19 and ringexpanding, rearrangement of the resulting ylide or metal-bound ylide to give the bridged-bicyclic ethers $Z-25$ and $E-25$.

\begin{tabular}{|c|c|c|c|c|}
\hline Entry & Catalyst(\%) ${ }^{[\mathrm{a}]}$ & Time (min) & Yield (\%) ${ }^{[b]}$ & $Z: E$ ratio $^{[c, d]}$ \\
\hline 1 & $\mathrm{Cu}(\text { tfacac })_{2}$ & 30 & 70 & $2.3: 1$ \\
\hline 2 & $\mathrm{Cu}(\text { hfacac })_{2}$ & 60 & 98 & 1.8:1 \\
\hline 3 & $\mathrm{Rh}_{2}(\mathrm{OAc})_{4}$ & 30 & 42 & $7.5: 1$ \\
\hline 4 & $\mathrm{Rh}_{2}(\mathrm{pfm})_{4}$ & 15 & 61 & $5.0: 1$ \\
\hline 5 & $\mathrm{Rh}_{2}(\mathrm{tfa})_{4}$ & 15 & 69 & 3.1:1 \\
\hline 6 & $\mathrm{Rh}_{2}(\mathrm{pfb})_{4}$ & 30 & 69 & 2.1:1 \\
\hline 7 & $\mathrm{Rh}_{2}(\text { tfacam })_{4}$ & 90 & 72 & $2.0: 1$ \\
\hline 8 & $\mathrm{Rh}_{2}(\mathrm{tpa})_{4}$ & 30 & 14 & $Z$ only \\
\hline \multicolumn{5}{|c|}{$\begin{array}{l}\text { [a] tfacac }=\mathrm{CF}_{3} \mathrm{COCHCOCH}_{3} ; \text { hfacac }=\mathrm{CF}_{3} \mathrm{COCHCOCF}_{3} ; \mathrm{pfm} \\
=\mathrm{HNCOC}_{3} \mathrm{~F}_{7} ; \mathrm{tfa}=\mathrm{O}_{2} \mathrm{CCF}_{3} ; \mathrm{pfb}=\mathrm{O}_{2} \mathrm{CC}_{3} \mathrm{~F}_{7} ; \text { tfacam }= \\
\mathrm{HNCOCF}_{3} ; \mathrm{tpa}=\mathrm{O}_{2} \mathrm{CCPh}_{3} \text {. [b] Combined isolated yield of } \boldsymbol{E}-\mathbf{2 5} \\
\text { and } Z-25 \text {. [c] Isomer ratio determined by }{ }^{1} \mathrm{H} \text { NMR analysis of the } \\
\text { crude reaction mixture. }\end{array}$} \\
\hline
\end{tabular}

It was not possible to identify a catalyst that would deliver both a high yield and good stereoselectivity. Fortunately, the less thermodynamically favourable isomer, $\boldsymbol{E}-\mathbf{2 5}$, could be converted into Z-25 by treatment with ethanethiol under radical conditions (Scheme 5). ${ }^{[17]}$ This discovery meant that the mixture of isomeric products obtained from the high-yielding reaction catalysed by copper(II) hexafluoroacetylacetonate could be converted into a single compound in high yield. The ketone Z-25 was crystalline (in racemic form) and so the structure of this compound was verified by single crystal $X$-ray crystallography. ${ }^{[18]}$

On the basis of the results obtained during the initial screen of various copper and rhodium complexes (Table 1), copper(II) hexafluoroacetylacetonate and rhodium(II) perfluorobutyramide were selected as catalysts in order to explore the influence of solvent and temperature on reaction yield and stereoselectivity (Table 2 and Scheme 5). These results revealed that copper(II) hexafluoroacetylacetonate catalysed reactions are generally 
lower yielding when performed in solvents (entries 1-5, Table 2) other than dichloromethane (entry 2, Table 1). However, higher stereoselectivity $(>20: 1, Z: E)$ is obtained when the reaction is performed in THF (entry 1, Table 2). We also discovered that rhodium(II) perfluorobutyramide catalysed reactions are low yielding when performed in solvents (entries 6-8, Table 2) other than dichloromethane (entry 4, Table 1), but the reactions are more stereoselective. However, when the reaction is performed in 1,2-dichloroethane at reflux (entry 9, Table 2), a higher yield $(68 \%)$ is obtained and the reaction is relatively stereoselective (6.3:1, Z:E).

\begin{tabular}{|c|c|c|c|c|c|}
\hline Entry & Catalyst $^{[\mathrm{a}]}$ & Solvent & Time (min) & Yield (\%) ${ }^{[b]}$ & $Z: E$ ratio $^{[c]}$ \\
\hline 1 & $\mathrm{Cu}(\text { hfacac })_{2}$ & THF & 30 & 39 & $>20: 1$ \\
\hline 2 & $\mathrm{Cu}(\text { hfacac })_{2}$ & PhMe & 30 & 49 & 3.0:1 \\
\hline 3 & $\mathrm{Cu}(\text { hfacac })_{2}$ & DCE & 30 & 77 & 2.9:1 \\
\hline 4 & $\mathrm{Cu}(\mathrm{hfacac})_{2}$ & $\mathrm{MeCN}$ & 150 & 22 & 1.3:1 \\
\hline 5 & $\mathrm{Cu}(\text { hfacac })_{2}$ & $\mathrm{Et}_{2} \mathrm{O}$ & 240 & 17 & $Z$ only \\
\hline 6 & $\mathrm{Rh}_{2}(\mathrm{pfm})_{4}$ & THF & 30 & 31 & $>20: 1$ \\
\hline 7 & $\mathrm{Rh}_{2}(\mathrm{pfm})_{4}$ & $\mathrm{MeCN}$ & 20 & 32 & $>20: 1$ \\
\hline 8 & $\mathrm{Rh}_{2}(\mathrm{pfm})_{4}$ & $\mathrm{PhMe}$ & 30 & 29 & $13: 1$ \\
\hline 9 & $\mathrm{Rh}_{2}(\mathrm{pfm})_{4}$ & DCE & 30 & 68 & 6.3:1 \\
\hline \multicolumn{6}{|c|}{$\begin{array}{l}\text { [a] hfacac }=\mathrm{CF}_{3} \mathrm{COCHCOCF}_{3} ; \mathrm{pfm}=\mathrm{HNCOC}_{3} \mathrm{~F}_{7} \text {. [b] Combined isolated } \\
\text { yield of } E-25 \text { and } Z-25 \text {. [c] Isomer ratio determined by }{ }^{1} \mathrm{H} \text { NMR analysis } \\
\text { of the crude reaction mixture. }\end{array}$} \\
\hline
\end{tabular}

Stereoselective construction of the bridged-bicyclic ether $\mathbf{Z}-25$ meant that elaboration of this compound to give the tricyclic cladiellin core could be investigated (Scheme 6). The synthetic strategy employed was analogous to the one used by us to synthesise related members of the cladiellin family of natural products. ${ }^{[5,13]}$ Conversion of the ketone $\boldsymbol{Z}-\mathbf{2 5}$ into the enol triflate followed by Heck coupling with ethyl vinyl ether afforded the diene 26. Intermolecular thermal Diels-Alder cycloaddition of the diene $\mathbf{2 6}$ with methyl vinyl ketone afforded tricyclic ketone $\mathbf{2 7}$ in excellent yield (69\% over three steps) as a mixture of exo and endo isomers (1:1 diastereomeric mixture at C-14). Attempted epimerisation of the diastereomeric mixture of ketones 27 using potassium carbonate, sodium hydroxide, sodium methoxide or potassium $t$-butoxide in methanol or ethanol, or by employing $\mathrm{DBU}$ in an aprotic solvent, failed to alter the ratio of diastereomers significantly. Fortunately, treatment of the mixture of isomers with $\mathrm{HCl}$ in methanol resulted in hydrolysis of the enol ether and cleavage of TBS ether with concomitant epimerisation at the C-14 stereocentre to give the crystalline diketone $\mathbf{2 8}$ as a single isomer in good yield. The structure of this compound (racemic form) was confirmed by single crystal X-ray crystallography. ${ }^{[18]}$
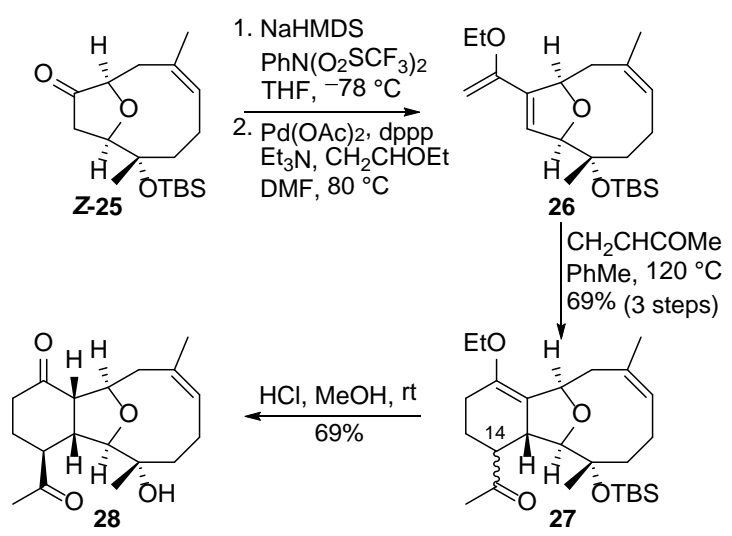

Scheme 6. Conversion of the bicyclic ketone $\mathbf{Z - 2 5}$ into the tricyclic diketone $\mathbf{2 8}$ using an intermolecular Diels-Alder cycloaddition reaction.

Selective functionalisation of the diketone $\mathbf{2 8}$ was necessary in order to elaborate this compound to give the proposed structure of sclerophytin F. Surprisingly, methylenation of the the diketone 28 using a conventional Wittig reaction afforded a separable mixture of the diene 29 (69\% yield) and the triene $\mathbf{3 0}$ (14\% yield), without formation of the product arising from monomethylenation of the methyl ketone (Scheme 7).

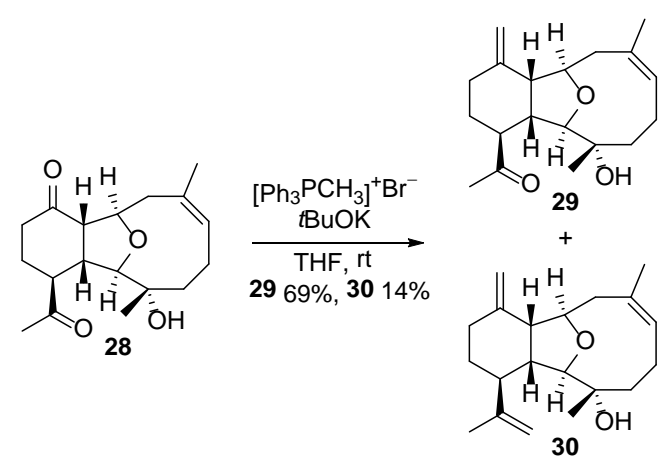

Scheme 7. Selective Wittig methylenation of the diketone 28

Protection of the tertiary alcohol in the diene $\mathbf{2 9}$ as a TES ether followed by addition of methylmagnesium chloride completed the carbon framework and delivered the alcohol $\mathbf{3 1}$ in good yield (Scheme 8). Side-chain deoxygenation was then performed using the procedure developed by Barrett and coworkers ${ }^{[19]}$ which has recently employed by Kim and co-workers and by us to prepare related cladiellin natural products. ${ }^{[5,13 b, 20]}$ Thus, acetylation of the alcohol followed by treatment of the ester with potassium, 18-crown-6 and t-butylamine in THF at room temperature afforded the silyl ether $\mathbf{3 2}$ and the alcohol $\mathbf{3 3}$ in a combined yield of $56 \%$. Subjection of the silyl ether 32 to acid-catalysed deprotection gave the crystalline alcohol $\mathbf{3 3}$ in high yield and its structure was confirmed by X-ray crystallography (Scheme 8). ${ }^{[18]}$ 

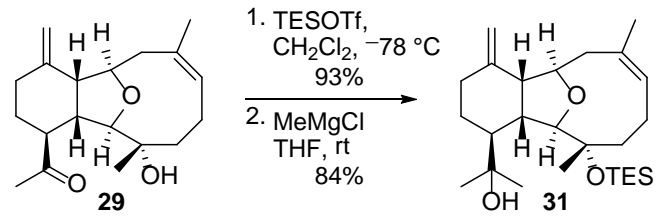

1. $\mathrm{Ac}_{2} \mathrm{O}, \mathrm{DMAP}, \mathrm{Et}_{3} \mathrm{~N}, 40^{\circ} \mathrm{C}$ 2. $\mathrm{K}, \mathrm{tBuNH}_{2}$

18-crown-6, THF, rt $49 \% 32,7 \% 33$ (2 steps)<smiles>C=C1CC[C@H](C(C)C)[C@]2(C)[C@H]1O[C@H]1C/C(C)=C/CC[C@H](OC#[SH])[C@H]12</smiles>

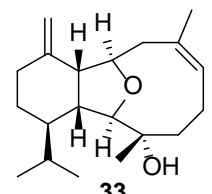

$\mathrm{HCl}, \mathrm{MeOH}, 0^{\circ} \mathrm{C}$

$95 \%$

Scheme 8. Introduction of the isopropyl side-chain by conversion of the methy ketone 29 into the alcohol 33.

The trisubstituted alkene of the diene $\mathbf{3 3}$ was epoxidised stereoselectively using $m$-chloroperbenzoic acid (Scheme 9). Attempted opening of the epoxide $\mathbf{3 4}$ to give a triol by exposure to scandium(III) triflate, ${ }^{[5 a]}$ afforded the C-6 allylic alcohol 35 instead. Treatment of the epoxide $\mathbf{3 4}$ with aqueous acid produced the allylic alcohol $\mathbf{3 5}$ in higher yield (77\%) along with the triol 36 in $15 \%$ yield. The structure of the crystalline allylic alcohol 35 was confirmed by X-ray crystallography. ${ }^{[18]}$

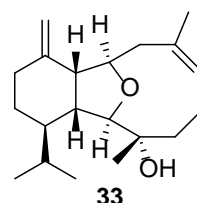

33

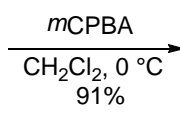

$\mathrm{KHSO}_{4}, \mathrm{Sc}(\mathrm{OTf}) 3$
$\mathrm{THF}, \mathrm{H}_{2} \mathrm{O}, \mathrm{rt}$
Scheme 9. Stereoselective and chemoselective epoxidation of the diene $\mathbf{3 3}$ and acid-catalysed ring opening of the resulting epoxide (34).

In order to prepare the compound that had been proposed to be sclerophytin $F$ (i.e. the triol 9) from the allylic alcohol 35 , it was necessary to invert the configuration at the C- 6 stereocentre (Scheme 10). Inversion of configuration was performed by sequential oxidation of the allylic alcohol $\mathbf{3 5}$ with the Dess-Martin periodinane and reduction of the intermediate enone under Luche conditions. This sequence delivered the required allylic alcohol 37 (57\% yield) along with the original C-6 diastereomer
35 (38\% yield). The synthesis of the triol 9 was completed by Sharpless asymmetric epoxidation to deliver the crystalline C-7 spiro-epoxide 38, the structure of which was confirmed by X-ray crystallography, ${ }^{[18]}$ and subsequent reductive opening at the less hindered position using diisobutylaluminium hydride (DIBAL-H).

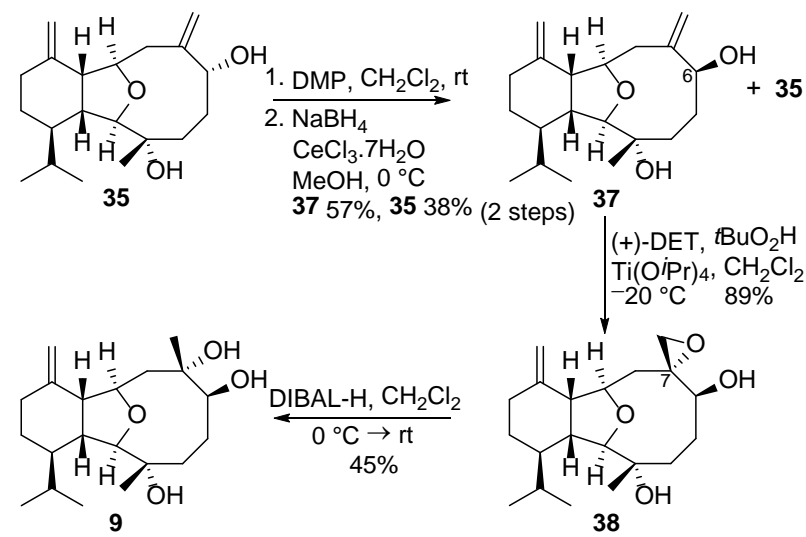

Scheme 10. Synthesis of the triol 9 corresponding to the structure of sclerophytin $\mathrm{F}$ as proposed by Friedrich and Paquette.

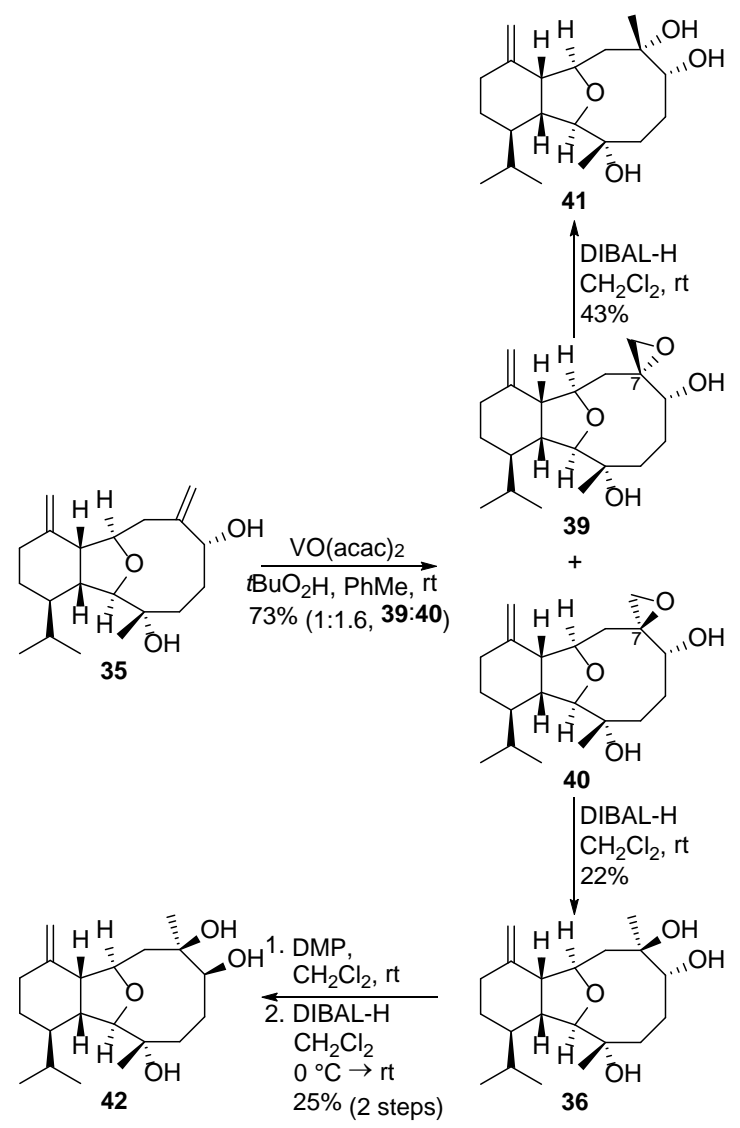

Scheme 11. Syntheses of the triols $\mathbf{3 6}, \mathbf{4 1}$ and $\mathbf{4 2}$ corresponding to the C-6 and C-7 diastereomers of proposed structure of sclerophytin F. 
Comparison of the ${ }^{1} \mathrm{H}$ and ${ }^{13} \mathrm{C}$ NMR data obtained for the trio 9 to those reported for natural sclerophytin $\mathrm{F}$ showed that these compounds are not the same. It was conceivable that we had prepared a diastereomer of sclerophytin $\mathrm{F}$ and so the syntheses of the diastereomeric triols possessing varying configurations at C-6 and C-7 were undertaken. All three compounds were prepared from the diol 35, a compound that served as an advanced intermediate for the synthesis of the triol $\mathbf{9}$.

Vanadium-catalysed epoxidation of the allylic alcohol $\mathbf{3 5}$ with $t$-butyl hydroperoxide afforded a separable mixture of the diastereomeric (C-7) crystalline spiro-epoxides 39 and 40 (1:1.6 ratio) in $73 \%$ yield (Scheme 11 ), the structures of which were confirmed by X-ray crystallography. ${ }^{18}$ Opening of the epoxide 39 at the less hindered position using DIBAL-H delivered the target triol $\mathbf{4 1}$ in modest yield. Treatment of the diastereomeric epoxide 40 under the same conditions produced the second target triol 36. The triol $\mathbf{3 6}$ had been obtained as a minor product upon treatment of the epoxide $\mathbf{3 4}$ with aqueous acid (Scheme 9).

The final compound required for comparison purposes, triol $\mathbf{4 2}$, was obtained by oxidation of the triol $\mathbf{3 6}$ using Dess-Martin periodinane and reduction of the resulting keto diol with DIBAL$\mathrm{H}$ (Scheme 11). Although the triol $\mathbf{4 2}$ was obtained in low yield over the two steps along with triol $\mathbf{3 6}$, a sufficient quantity of this compound was prepared to enable full characterization.

\begin{tabular}{|c|c|c|c|c|c|}
\hline Position & $\mathrm{F}^{[\mathrm{a}]}$ & $\mathbf{9}^{[b, c]}$ & $36^{[c, d]}$ & $41^{[c, d]}$ & $42^{[c, d]}$ \\
\hline 1 & 45.4 & 42.3 & 44.4 & 43.3 & 44.1 \\
\hline 2 & 91.9 & 87.0 & 91.8 & 90.4 & 90.8 \\
\hline 3 & 86.6 & $73.9 / 75.1$ & $74.4 / 76.3$ & $73.6 / 74.7$ & $74.8 / 75.5$ \\
\hline 4 & 35.9 & 33.2 & 34.2 & 33.2 & 35.1 \\
\hline 5 & 30.5 & 29.8 & 30.8 & 28.2 & 29.2 \\
\hline 6 & 80.1 & 75.4 & 79.8 & 76.8 & 76.3 \\
\hline 7 & 77.0 & $73.9 / 75.1$ & $74.4 / 76.3$ & $73.6 / 74.7$ & $74.8 / 75.5$ \\
\hline 8 & 45.8 & 45.2 & 44.2 & 46.3 & 45.6 \\
\hline 9 & 78.2 & 75.8 & 77.4 & 76.1 & 77.5 \\
\hline 10 & 52.9 & 47.8 & 48.5 & 48.4 & 50.8 \\
\hline 11 & 147.6 & 146.1 & 146.2 & 146.0 & 146.7 \\
\hline 12 & 31.4 & 30.3 & 28.7 & 30.4 & 30.9 \\
\hline 13 & 24.7 & 24.8 & 25.0 & 24.8 & 24.9 \\
\hline 14 & 43.9 & 40.5 & 41.8 & 41.2 & 42.1 \\
\hline 15 & 29.1 & 29.4 & 29.0 & 29.5 & 29.4 \\
\hline 16 & 21.9 & 22.2 & 22.0 & 22.1 & 22.0 \\
\hline 17 & 15.7 & 20.7 & 18.4 & 19.8 & 18.5 \\
\hline 18 & 23.2 & 28.5 & 27.9 & 29.8 & 27.5 \\
\hline 19 & 22.3 & 22.7 & 26.5 & 28.3 & 26.1 \\
\hline 20 & 109.3 & 107.9 & 109.7 & 108.8 & 108.9 \\
\hline
\end{tabular}

The ${ }^{1} \mathrm{H}$ and ${ }^{13} \mathrm{C}$ NMR data for the triols $9,36,41$ and 42 were compared to the data reported for sclerophytin $\mathrm{F}$ (Table 3). ${ }^{\left[{ }^{[3]}\right.}$ Significant differences between the ${ }^{13} \mathrm{C}$ NMR data for all four triols and those of sclerophytin $\mathrm{F}$ were immediately obvious, particularly between the ${ }^{13} \mathrm{C}$ NMR signals for $\mathrm{C}-3, \mathrm{C}-6$ and $\mathrm{C}-7$. The ${ }^{13} \mathrm{C}$ chemical shift for $\mathrm{C}-3$ signal appears at $86.6 \mathrm{ppm}$ for sclerophytin $\mathrm{F}$ but the chemical shifts for the corresponding carbon in the triols 9, 36, $\mathbf{4 1}$ and $\mathbf{4 2}$ lie below 76.3 ppm. A similar but less pronounced discrepancy is evident with the regard to the ${ }^{13} \mathrm{C}$ NMR chemical shifts of signals for C- 6 and C-7, which appear at lower values in the case of triols 9, 36, 41 and 42 than in sclerophytin F. The chemical shifts of signals arising from carbons at the C-1, C-4, C-10, C-14, C-17 and C-18 positions in the ${ }^{13} \mathrm{C}$ NMR spectrum of sclerophytin $\mathrm{F}$ also differ significantly from those of the corresponding peaks in the ${ }^{13} \mathrm{C}$ NMR spectra of triols $\mathbf{9}, \mathbf{3 6}, \mathbf{4 1}$ and $\mathbf{4 2}$.

The four diastereomeric triols $(\mathbf{9}, \mathbf{3 6}, 41$ and 42$)$ possessing $S$ configuration at $\mathrm{C}-3$ had been prepared and none of these compounds was sclerophytin F. The fact that these triols did not correspond to natural product meant that further comparison of the NMR data for related compounds was required in order to deduce the structure of sclerophytin $\mathrm{F}$.

In a further attempt to identify sclerophytin $\mathrm{F}$, the ${ }^{1} \mathrm{H}$ and ${ }^{13} \mathrm{C}$ NMR data for the four triols possessing $R$ configuration at $\mathrm{C}-3$ were considered. One of the compounds in this group is sclerophytin A and it is clear that this natural product is not the same as sclerophytin F. We prepared the diastereomeric triol $\mathbf{4 4}$ (7-epi-sclerophytin A) by diastereoselective dihydroxylation of the diene $43^{[21]}$ a compound that had served as a key intermediate during our synthesis of vigulariol (Scheme 12). ${ }^{[5 e, 13 a]}$

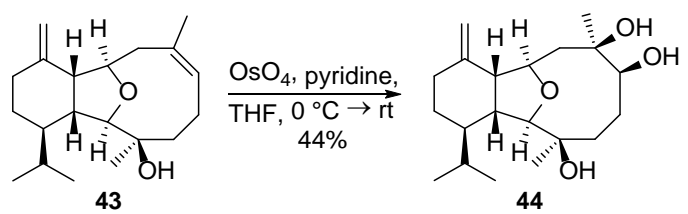

Scheme 12. Stereoselective dihydroxylation of the diene $\mathbf{4 3}$ to give the triol $\mathbf{4 4}$.

Sclerophytin A, 7-epi-sclerophytin A (44) plus two other diastereomeric compounds with varying configurations at C-6 and $\mathrm{C}-7$ had been prepared by Paquette and co-workers. ${ }^{[4, f]}$ These workers reported that reduction of the hydroxyketone $\mathbf{4 5}$ delivers the triols $\mathbf{4 4}$ and $\mathbf{4 6}$ and that the choice of reducing agent dictates the stereochemical outcome of the reaction (Scheme 13). Comparison of the ${ }^{1} \mathrm{H}$ and ${ }^{13} \mathrm{C}$ NMR data for our triol $\mathbf{4 4}$ with those reported by Paquette and co-workers revealed that our triol is identical to the compound produced by reduction of the hydroxyketone $\mathbf{4 5}$ using DIBAL-H but identifed as the triol 46 by Paquette and co-workers. ${ }^{[4,, f]}$ Given that the compound prepared by us is known to be the syn 1,2-diol resulting from dihydroxylation of a Z-alkene, we are confident that the structures assigned to the triols $\mathbf{4 4}$ and $\mathbf{4 6}$ by Paquette and coworkers are incorrect and that the compound produced by 
reduction of the hydroxyketone 45 with DIBAL-H is in fact the triol $\mathbf{4 4}$ rather than the triol $\mathbf{4 6 .}$

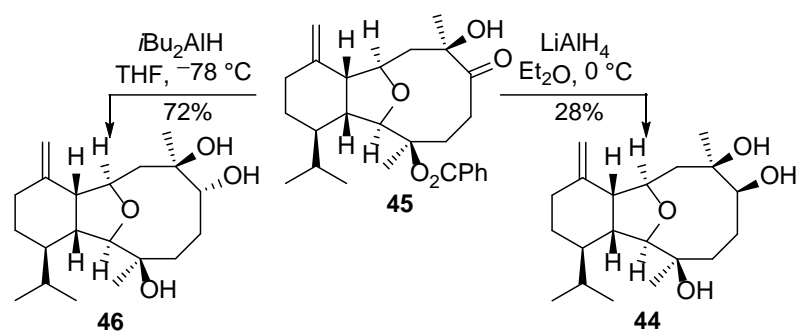

Scheme 13. Reduction of the hydroxy ketone $\mathbf{4 5}$ to give the diastereomeric triols $\mathbf{4 4}$ and $\mathbf{4 6}$ with assignments as reported by Paquette and co-workers.

The ${ }^{1} \mathrm{H}$ and ${ }^{13} \mathrm{C}$ NMR data for sclerophytin $\mathrm{F}$ were compared to those of sclerophytin $A$, the triol $\mathbf{4 4}$ and the two other diastereomeric triols prepared by Paquette and co-workers that possess $R$ configuration at $\mathrm{C}-3 .{ }^{[4,, f]}$ The NMR data for the four triols did not match those reported for sclerophytin $\mathrm{F}$.

At this stage, six of the eight diastereomeric triols with varying configurations at C-3, C- 6 and C-7 had been prepared by us and the remaining two had been reported by Paquette and coworkers. None of these diastereomeric triols was sclerophytin $F$ and so in order to identify the natural product it was necessary to re-analyse and compare the original NMR data to those reported for closely related cladiellin natural products.

Inspection of the data reported by Alam and co-workers for sclerophytins $E$ and $F$ reveals some anomalies and raises doubts about the assignments for both compounds. ${ }^{[3]}$ The first problem is that the mass spectrum given for sclerophytin $\mathrm{F}$ is not consistent with the assigned molecular formula $\left(\mathrm{C}_{20} \mathrm{H}_{34} \mathrm{O}_{4}\right)$. The molecular ion is given as 363 whereas the mass of the molecular ion for sclerophytin $\mathrm{F}$ should be 338 , if the molecular formula is correct. The heaviest ion in the mass spectrum for sclerophytin E appears at 338 which could mean that ionisation has resulted in loss of the acetate group or that this compound is actually a triol with molecular formula $\mathrm{C}_{20} \mathrm{H}_{34} \mathrm{O}_{4}$. Finally, the chemical shifts for the carbon framework signals in the ${ }^{13} \mathrm{C}$ NMR spectra for sclerophytins $\mathrm{E}$ and $\mathrm{F}$ are almost identical and the chemical shifts of the signals corresponding to $\mathrm{C}-3$ differ by only $0.3 \mathrm{ppm}$, which is inconsistent with sclerophytin $\mathrm{E}$ being the $\mathrm{C}-3$ acetate of sclerophytin F. A chemical shift difference of several ppm would be expected on the basis of the observed differences in the ${ }^{13} \mathrm{C}$ NMR spectra of sclerophytins $A(3)$ and $B(4)$, for example (Figure 1). The ${ }^{1} \mathrm{H}$ NMR spectra for sclerophytins $E$ and $\mathrm{F}$ are also very similar and the chemical shifts and coupling constants are identical for many signals. It should be appreciated that comparison of data for sclerophytins $E$ and $F$ is complicated by the fact that the original publication describing their isolation contains significant typographical errors. ${ }^{[3]}$

Inspection of the ${ }^{13} \mathrm{C}$ NMR data for the closely related natural products 3-6 (Figure 1), ${ }^{[2,6,7]}$ the structures of which have been verified by total synthesis or X-ray crystallography, and comparison with the ${ }^{13} \mathrm{C}$ NMR data for sclerophytin $F$ reveals some interesting trends (Table 4). It is clear that the ${ }^{13} \mathrm{C}$ NMR data for sclerophytin $F$ are very similar $(\leq 0.3 \mathrm{ppm}$ chemical shift difference) to those of sclerophytin A, apart from the chemical shifts of the signals arising from $\mathrm{C}-2-\mathrm{C}-5$ and $\mathrm{C}-18$. This observation suggests the compounds are very similar but the $\mathrm{C}$ 3 hydroxyl group of sclerophytin $\mathrm{F}$ is functionalised in some way. Another significant observation is that the ${ }^{13} \mathrm{C}$ NMR data for sclerophytins $\mathrm{E}$ and $\mathrm{F}$ are very similar to those of sclerophytin $\mathrm{C}$ (7), especially with regard to the signals arising from C-2-C-5 and $\mathrm{C}-18$. The only major differences are between the signals resulting from the $\mathrm{C}-6-\mathrm{C}-9$, as a consequence of the $\mathrm{C}-8$ hydroxyl group in sclerophytin C (Table 4).

\begin{tabular}{|c|c|c|c|c|c|c|}
\hline Position & $3^{[a]}$ & $4^{[\mathrm{a}]}$ & $5^{[b, c]}$ & $6^{[\mathrm{c}-\mathrm{e}]}$ & $F^{[f]}$ & $7^{[f]}$ \\
\hline 1 & 45.2 & 45.5 & 44.6 & 45.3 & 45.4 & 45.0 \\
\hline 2 & 90.5 & 90.5 & 90.5 & 91.1 & 91.9 & 91.4 \\
\hline 3 & 74.8 & 74.8 & 74.9 & 74.4 & 86.6 & 86.2 \\
\hline 4 & 39.9 & 39.8 & 41.0 & 40.9 & 35.9 & 34.5 \\
\hline 5 & 29.4 & 28.1 & 30.0 & 27.2 & 30.5 & 29.5 \\
\hline 6 & 79.9 & 85.0 & 90.5 & 88.4 & 80.1 & 77.0 \\
\hline 7 & 77.0 & 75.9 & 76.1 & 76.1 & 77.0 & 79.6 \\
\hline 8 & 45.4 & 45.5 & 45.1 & 45.1 & 45.8 & 79.5 \\
\hline 9 & 78.2 & 78.0 & 78.1 & 78.6 & 78.2 & 81.1 \\
\hline 10 & 52.6 & 53.2 & 53.0 & 53.8 & 52.9 & 52.5 \\
\hline 11 & 147.9 & 147.9 & 147.9 & 148.4 & 147.6 & 148.6 \\
\hline 12 & 31.6 & 31.9 & 31.6 & 31.9 & 31.4 & 31.6 \\
\hline 13 & 24.9 & 24.8 & 25.9 & 25.2 & 24.7 & 24.8 \\
\hline 14 & 43.7 & 43.6 & 43.7 & 44.0 & 43.9 & 43.7 \\
\hline 15 & 29.1 & 29.0 & 29.0 & 29.3 & 29.1 & 29.0 \\
\hline 16 & 16.0 & 16.1 & 15.9 & 15.7 & 15.7 & 16.2 \\
\hline 17 & 22.0 & 21.9 & 22.0 & 22.1 & 21.9 & 21.9 \\
\hline 18 & 30.3 & 30.2 & 29.4 & 29.9 & 23.2 & 23.0 \\
\hline 19 & 23.1 & 23.7 & 23.9 & 24.8 & 22.3 & 17.7 \\
\hline \multirow[t]{3}{*}{20} & 109.1 & 109.2 & 109.1 & 109.2 & 109.3 & 109.9 \\
\hline & & 171.8 & 57.0 & 64.8 & & 169.5 \\
\hline & & 21.5 & & 15.3 & & 22.7 \\
\hline
\end{tabular}

[a] Data reported in ref. 2. [b] Data reported in ref. 6, but peaks for C-3, C7, C-13, C-18 and C-19 appear to have been assigned incorrectly and have been corrected. [c] Structure confirmed by X-ray analysis. [d] Data reported in ref. 7. [e] The ${ }^{13} \mathrm{C}$ NMR spectrum was recorded in $\mathrm{C}_{6} \mathrm{D}_{6}$. [f] Data reported in ref. 3.

Comparison of the ${ }^{13} \mathrm{C}$ NMR data for sclerophytins $\mathrm{E}$ and $\mathrm{F}$ with those of the other sclerophytin natural products reassigned by Friedrich and Paquette as having $S$ configuration at $\mathrm{C}-3$, shows that the compounds are very similar (Table 5). Significant differences in chemical shift are restricted to signals corresponding to $\mathrm{C}-5-\mathrm{C}-7$, suggesting that the C-6 substituent accounts for the structural differences between the compounds. 


\begin{tabular}{|c|c|c|c|c|c|}
\hline Position & & $E^{[a, b]}$ & $\begin{array}{l}\text { 6-ethoxy } \\
\text { clerophytin } E^{[c]}\end{array}$ & $\begin{array}{l}\text { 6-isovaleroyl } \\
\text { sclerophytin } E^{[c]}\end{array}$ & litophynin $E^{[c]}$ \\
\hline 1 & 45.4 & 45.2 & 45.3 & 45.8 & 45.4 \\
\hline 2 & 91.9 & $92.0 \quad(91.9)$ & 92.1 & 92.1 & 92.0 \\
\hline 3 & 86.6 & $86.3 \quad(86.7)$ & 86.4 & 86.7 & 86.4 \\
\hline 4 & 35.9 & $36.1 \quad(36.0)$ & 36.6 & 35.7 & 36.1 \\
\hline 5 & 30.5 & 30.4 (30.6) & 27.5 & 29.3 & 30.4 \\
\hline 6 & 80.1 & $80.1 \quad(79.8)$ & 88.3 & 84.5 & 80.1 \\
\hline 7 & 77.0 & $77.0 \quad$ (76.8) & 75.9 & 75.5 & 76.8 \\
\hline 8 & 45.8 & $45.7 \quad(46.0)$ & 44.9 & 45.8 & 45.8 \\
\hline 9 & 78.2 & 78.2 (78.4) & 78.5 & 78.1 & 78.2 \\
\hline 10 & 52.9 & $52.9 \quad(53.6)$ & 53.9 & 53.8 & 53.6 \\
\hline 11 & 147.6 & $147.6(147.7)$ & 147.8 & 147.6 & 147.6 \\
\hline 12 & 31.4 & $31.4 \quad(31.5)$ & 31.5 & 31.5 & 31.4 \\
\hline 13 & 24.7 & 24.8 (24.7) & 24.6 & 24.6 & 24.6 \\
\hline 14 & 43.9 & 43.9 (44.0) & 44.0 & 43.8 & 43.8 \\
\hline 15 & 29.1 & $29.0 \quad(29.1)$ & 29.0 & 29.0 & 29.0 \\
\hline 16 & 15.7 & 16.1 & 15.5 & 15.4 & 15.6 \\
\hline 17 & 21.9 & $21.9 \quad(22.0)$ & 21.9 & 21.9 & 21.9 \\
\hline 18 & 23.2 & $23.2 \quad(23.2)$ & 23.1 & 22.9 & 23.2 \\
\hline 19 & 22.3 & $22.6 \quad(22.3)$ & 23.8 & 23.8 & 22.6 \\
\hline \multirow[t]{7}{*}{20} & 109.3 & $109.3(109.4)$ & 109.5 & 109.5 & 109.3 \\
\hline & & $170.1(169.2)$ & 169.9 & 169.6 & 172.5 \\
\hline & & $22.7 \quad(22.5)$ & 22.3 & 22.4 & 37.3 \\
\hline & & & 64.6 & 173.9 & 18.3 \\
\hline & & & 15.5 & 43.8 & 13.7 \\
\hline & & & & 25.8 & \\
\hline & & & & 22.9 & \\
\hline
\end{tabular}

The ${ }^{1} \mathrm{H}$ and ${ }^{13} \mathrm{C}$ NMR data reported for sclerophytins $\mathrm{E}$ and $\mathrm{F}$ are almost identical and sclerophytin $F$ is clearly not a diastereomer of sclerophytin A. Complete analysis of the ${ }^{13} \mathrm{C}$ NMR data for sclerophytin A (3) and the seven other diastereomeric triols having $R$ or $S$ configuration at C-3, C-6 and $\mathrm{C}-7$, and comparison of these data to those of the natural products 4-7, 6-ethoxy sclerophytin E, 6-valeroyl sclerophytin E and litophynin $E$ leads us to the conclusion that sclerophytin $F$ is simply re-isolated sclerophytin $\mathrm{E}$, a finding that is consistent with the original mass spectrometry data. ${ }^{[3]}$ Based on all the available data, and in particular comparison of the ${ }^{13} \mathrm{C} N M R$ data for sclerophytin $E$ with those of sclerophytins $A$ and $C$, it is clear that sclerophytin E is the C-3 acetate of sclerophytin A. This is the structure that was assigned to sclerophytin $\mathrm{E}$ by Alam and coworkers $^{[3]}$ and by Rao, Faulkner and co-workers, ${ }^{[9]}$ prior to the structural reassignment of several sclerophytins by Friedrich and Paquette in $2002 .{ }^{[11]}$ The fact that sclerophytins $E$ and $F$ are the same compound is particularly evident when appreciates that the ${ }^{13} \mathrm{C}$ NMR data for the triols $9,36,41$ and 42 show a much lower degree of homology than do the ${ }^{13} \mathrm{C} N M R$ data for sclerophytins $E$ and $F$, even though the four triols have simple diastereomeric relationships (Table 3).

The failure of Alam and co-workers to report the signals corresponding the acetate group in the ${ }^{13} \mathrm{C}$ NMR spectrum of sclerophytin $\mathrm{F}$ is puzzling, but could be explained by overlap of the ${ }^{13} \mathrm{C}$ NMR signal of the acetate methyl group ( $\delta 22.6 \mathrm{ppm}$ ) with that of C-19 ( $\delta 22.7 \mathrm{ppm})$ and the use a very weak sample leading to a low intensity signal for the carbonyl group. In the ${ }^{1} \mathrm{H}$ NMR spectrum of sclerophytin $F$, the signal arising from the acetate methyl group (reported to appear at $\delta 2.02 \mathrm{ppm}$ in the ${ }^{1} \mathrm{H}$ NMR spectrum of sclerophytin E) could have been attributed to, or obscured by, the presence of water in the NMR sample. ${ }^{[22]}$

The discovery that sclerophytins $E$ and $F$ are the same compound and that the original structural assignment for sclerophytin E is correct means that we are able to correct the structures of related sclerophytin-type natural products that were reassigned incorrectly by Friedrich and Paquette. ${ }^{[11]}$ Thus, sclerophytin E/F (47) is the C-3 acetate of sclerophytin A and 6ethoxy sclerophytin E, 6-isovaleroyl sclerophytin E are compounds 48 and 49 i.e. sclerophytin $E$ has the structure proposed originally by Alam and co-workers and the others have the structures assigned by Rao, Faulkner and co-workers (Figure 3). ${ }^{[9]}$ The very close correlation between the ${ }^{13} \mathrm{C}$ NMR data for sclerophytin $E$ and litophynin $E$ suggests that the only difference between these compounds is the type of ester group at C-3 and that litophynin E is ester $\mathbf{5 0}$, which is the C-7 diastereomer of the compound proposed by Ochi and coworkers following their isolation of the natural product. ${ }^{[8 \mathrm{a}]}$ It then follows that 6-acetoxy litophynin $E$ is the diester $\mathbf{5 1}$ (Figure 3).

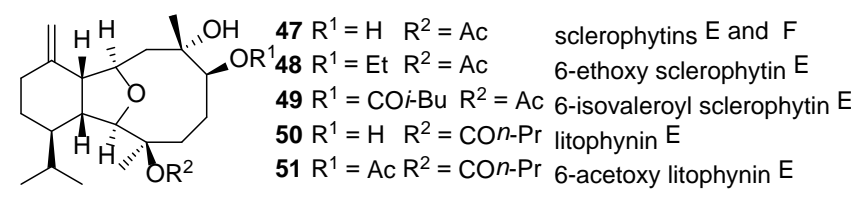

Figure 3. Reassigned structures of the sclerophytins.

\section{Conclusions}

The compound purported to be sclerophytin $F$ and three diastereomeric (at C-6 and C-7) triols have been synthesised. The NMR data for each of these compounds do not match the data reported for sclerophytin F. Analysis of the NMR data for the four known triols that are diastereomers with respect to their configuration at $\mathrm{C}-3$, shows that none of these compounds is sclerophytin $\mathrm{F}$ either. Careful re-analysis of the ${ }^{13} \mathrm{C}$ NMR data for the natural products 3-7 plus the NMR data for sclerophytin $E$, sclerophytin F, 6-ethoxy sclerophytin E, 6-isovaleroyl sclerophytin $E$ and litophynin $E$ leads us to the conclusion that sclerophytins $E$ and $F$ are the same compound. The structures proposed by Friedrich and Paquette for sclerophytin E, sclerophytin $\mathrm{F}$ and related natural products are incorrect and 
these compounds are those shown in Figure 3. All of the sclerophytins possess the sclerophytin A skeleton but are esterified at the C-3 hydroxyl group and/or functionalized at the C-6 hydroxyl site i.e. none of the natural sclerophytins possesses inverted configuration at C-3. The structures of compounds $\mathbf{4 7 - 5 1}$ are those proposed previously by Rao, Faulkner and co-workers. ${ }^{[9]}$

\section{Acknowledgements}

The authors thank the University of Glasgow for studentship funding (LD) and Dr Brian Smith (University of Glasgow) for performing NMR spectroscopy on the triol 9. We thank $\mathrm{Dr}$ Stewart T Hayes for preparing 7-epi-sclerophytin A (44).

Keywords: carbenoid $\bullet$ rearrangement $\bullet$ natural product $\bullet$ total synthesis $\bullet$ structure elucidation

[1] a) P. Bernardelli, L. A. Paquette, Heterocycles, 1998, 49, 531; b) A. J. Welford, I. Collins, J. Nat. Prod. 2011, 74, 2318.

[2] P. Sharma, M. Alam, J. Chem. Soc., Perkin Trans. 1 1988, 2537.

[3] M. Alam, P. Sharma, A. S. Zektzer, G. E. Martin, X. Ji, D. van der Helm, J. Org. Chem. 1989, 54, 1896. This paper contains several typographical errors in text and experimental data.

[4] a) L. A. Paquette, O. M. Moradei, P. Bernardelli, T. Lange, Org. Lett. 2000, 2, 1875; b) D. Friedrich, R. W. Doskotch, L. A. Paquette, Org. Lett. 2000, 2, 1879; c) L. E. Overman, L. D. Pennington, Org. Lett. 2000 2, 2683; d) F. Gallou, D. W. C. MacMillan, L. E. Overman, L. A. Paquette, L. D. Pennington, J. Yang, Org. Lett. 2001, 3, 135; e) L. A Paquette, Chem. Rec. 2001, 1, 311; f) P. Bernardelli, O. M. Moradei, D. Friedrich, J. Yang, F. Gallou, B. P. Dyck, R. W. Doskotch, T. Lange, L. A. Paquette, J. Am. Chem. Soc. 2001, 123, 9021; g) D. W. C MacMillan, L. E. Overman, L. D. Pennington, J. Am. Chem. Soc. 2001 123, 9033.

[5] a) B. Wang, A. P. Ramirez, J. J. Slade, J. P. Morken J. Am. Chem. Soc. 2010, 132, 16380; b) M. T. Crimmins, C. S. Stauffer, M. C. Mans, Org. Lett. 2011, 13, 4890; c) J. S. Clark, R. Berger, S. T. Hayes, H. M. Senn, L. J. Farrugia, L. H. Thomas, A. J. Morrison, L. Gobbi, J. Org. Chem. 2013, 78, 673

[6] N. S. Sarma, R. Chavakula, I. N. Rao, R. Kadirvelraj, T. N. G. Row, I. Saito, J. Nat. Prod. 1993, 56, 1977. The structure assigned to sclerophytin $\mathrm{F}$ methyl ether in this paper is incorrect with regard to the configuration at $\mathrm{C}-3$. Crystallographic data lodged with the Cambridge
Crystallographic Data Centre are consistent with the diol $\mathbf{5}$, which is the methyl ether of sclerophytin A. For further datails, see ref. 11

[7] J. Su, Y. Zheng, L. Zeng, E. O. Pordesimo, F. J. Schmitz, M. B. Hossain, D. van der Helm, J. Nat. Prod. 1993, 56, 1601.

[8] a) M. Ochi, K. Yamada, K. Futatsugi, H. Kotsuki, K. Shibata, Chem. Lett 1990, 19, 2183; b) T. Miyamoto, K. Yamada, N. Ikeda, T. Komori, R. Higuchi, J. Nat. Prod. 1994, 57, 1212.

[9] C. B. Rao, D. S. Rao, C. Satyanarayana, D. V. Rao, K. E. Kassühlke D. J. Faulkner, J. Nat. Prod. 1994, 57, 574.

[10] C.-J. Tai, J.-H. Su, C.-Y. Huang, M.-S. Huang, Z.-H. Wen, C.-F. Dai, J. H. Sheu, Mar. Drugs 2013, 11, 788.

[11] D. Friedrich, L. A. Paquette, J. Nat. Prod. 2002, 65, 126

[12] For preliminary results, see: J. S. Clark, L. Delion, L. J. Farrugia, Org Lett. 2014, 16, 4300

[13] a) J. S. Clark, S. T. Hayes, C. Wilson, L. Gobbi, Angew. Chem. Int. Ed 2007, 46, 437; b) J. S. Clark, R. Berger, S. T. Hayes, L. H. Thomas, A J. Morrison, L. Gobbi, Angew. Chem. Int. Ed. 2010, 49, 9867.

[14] a) G. Matsuo, H. Kadohama, T. Nakata, Chem. Lett. 2002, 148; b) J. S. Clark, S. T. Hayes, A. J. Blake, L. Gobbi, Tetrahedron Lett. 2007, 48, 2501

[15] a) P.-T. Ho, R. J. Kolt, Can. J. Chem. 1982, 60, 663. b) G. Berti, P. Caroti, G. Catelani, L. Monti, , Carbohydr. Res. 1983, 124, 35.

[16] a) Pirrung, M. C.; Werner, J. A. J. Am. Chem. Soc. 1986, 108, 6060; b) E. J. Roskamp, C. R. Johnson J. Am. Chem. Soc. 1986, 108, 6062; c) J. S. Clark, Tetrahedron Lett. 1992, 33, 6193; d) F. G.; West, B. N. Naidu, R. W. Tester, J. Org. Chem. 1994, 59, 6892. (d) F. P. Marmsäter, J. A Vanecko, F. G. West, Org. Lett. 2004, 6, 1657; (e) G. K. Murphy, C Stewart, F. G. West, Tetrahedron 2013, 69, 2667

[17] a) J. S. Clark, A. G. Dossetter, A. J. Blake, W.-S. Li, W. G. Whittingham, Chem. Commun. 1999, 749; b) R. Annunziata, M. Cinquini, F. Cozzi, C. Gennari and L. Raimondi, J. Org. Chem., 1987, 52, 4674.

[18] The structures of the crystalline compounds ( \pm )-Z-25 (CCDC 1033439), ( \pm )-28 (CCDC 1031582), 33 (CCDC 1033441), 35 (CCDC 1031581) and 38-40 (CCDC 1031583, CCDC 1033444, CCDC1033443) were confirmed by $\mathrm{X}$-ray crystallography and the data have been lodged with The Cambridge Crystallographic Data Centre. Details can be found in Supporting Information and data can be obtained free of charge from The Cambridge Crystallographic Data Centre (www.ccdc.cam.ac.uk).

[19] A. G. M. Barrett, C. R. A. Godfrey, D. M. Hollinshead, P. A. Prokopiou, D. H. R. Barton, R. B. Boar, L. Joukhadar, J. F. McGhie, S. C. Misra, J. Chem. Soc., Perkin Trans. 1 1981, 1501.

[20] H. Kim, H. Lee, J. Kim, S. Kim, D. Kim, J. Am. Chem. Soc. 2006, 128, 15851.

[21] The triol 44 was prepared by $\mathrm{Dr}$ Stewart $\mathrm{T}$ Hayes, PhD Thesis, University of Nottingham, 2008

[22] The original NMR data for sclerophytins $E$ and $F$ are no longer available because both corresponding authors in reference 3 are deceased. 